\title{
La nueva derecha en El Salvador (parte primera)
}

\author{
Carlos F. Hernández M.
}

\section{ORIGEN DE LA NUEVA DERECHA EN EL SALVADOR}

En la década de los años setenta, paralelamente a la crisis del modelo de hegemonía económica y político-social de la derecha tradicional, inició el surgimiento de una nueva fuerza político-social, cuyos integrantes, en alguna medida, están relacionados por vínculos de afinidad, consanguinidad o simples relaciones laborales de dependencia con los intereses económicos oligárquicos nacionales; fuerza que se identifica porque se centra en el sentido de enfatizar, en la necesidad de la modernización del capital, como medio que facilitará la generación de condiciones que en el mediano plazo, permitan llegar a la economía salvadorefía a una situación de crecimiento, por medio del cual se solventarán las actuales causas que originan la crisis, factores que al desaparecer del escenario nacional, contribuirán grandemente al logro de una estabilidad político-social, como condición previa para alcanzar el desarrollo económico, político y social de la nación. Esta fuerza que expresa tal tipo de discurso, es lo que de aqui en adelante se identificará como "Nueva derecha", nueva en el orden de su reciente surgimiento y lo de derecha, por presentar un modelo que a nivel económico y político-social, pretende mantener la valides del modelo de acumulación vigente, a través de incorporarle niveles de modernización, en todos los órdenes, que faciliten la vigencia y reproducción del modo de producción capitalista, que ha hecho posible la concentración de la riqueza y el ingreso en los miembros de la derecha tradicional.

Su existencia en el escenario nacional, puede ser considerado en dos sentidos: uno funcional, como una consecuencia de la crisis; otro dialéctico, como una respuesta a la misma crisis, cuyas manifestaciones 
a nivel de la sociedad, se hicieron por medio de un conjunto de expresiones que revistieron mayor dramatismo, amplitud y prolongación. Dramatismo en el sentido del conjunto de manifestaciones, que se presentaron con mayor evidencia y claridad, que no permitieron dudas, que se iniciaba un proceso de crisis en los órdenes económico, político, social e ideológico. Amplitud de la crisis, en el marco de que las manifestaciones de la misma comprometen a todos los sectores de la sociedad, desde esa época. Prolongación en el orden de presencia desde ese momento hasta el presente, sin que se visualice una solución a la crisis, en el futuro inmediato.

En tal orden de cosas el surgimiento de la nueva derecha, reviste las características propias de un proceso, lento pero progresivo, cuyas primeras manifestaciones no se pueden ubicar con precisión cronológica, sino que en el marco de una nueva coyuntura política, cuyo conjunto de expresiones encubrieron inicialmente las primeras manifestaciones de dicho actor, por no ser las dominantes; pero que, en la medida en que la crisis, sin dejar de incidir en el orden político-social, se hizo sentir en el orden económico, las expresiones de la nueva derecha fueron adquiriendo mayores niveles de atención y primacia, en el escenario nacional. Es así, como en este marco de hechos, que se puede ubicar el surgimiento de la nueva derecha, como actor políticosocial, cronológicamente ubicándose al ínicio de la década de los años ochenta.

Con la finalidad de promover mayor credibilidad y respaldo a las propuestas que ha expresado, tănto en el orden económico, como político, social e ideológico, los integrantes de esta fuerza, contando con la cooperación económica e ideológica de la nueva derecha estadounidense, inician la fundación de una serie de organizaciones, que sirven a sus propósitos en varios sentidos, como una manera de institucionalizar en la sociedad civil su existencia, en el orden de proporcionar seriedad a sus propuestas, pues todas o la mayoria se colocan la etiqueta de "centros de investigación", y por último como base de una estructura orgánica, que les permita en el corto plazo crecer, desarrollarse y consolidar su presencia e influencia.

Estas instituciones creadas por la nueva derecha, han desempenado una función parecida a la de los "think thank" de la sociedad estadounidense, no viéndose esto en el sentido de una investigación y formulación teórica del diagnóstico de la crisis y propuestas de solución a la misma, sino que tal función la han pretendido realizar por la acción de efectuar una adecuación de los modelos, tanto a nivel del diagnóstico, como de las soluciones de la crisis, propias de los paises ca- 
pitalistas ricos, desarrollados e industrializados a nuestra realidad que corresponde a la de un pais capitalista dependiente, pobre, subdesarrollado, atrasado y sobretodo que vive un conflicto político-militar, que ya lleva diez anos al presente, en su evolución.

En este sentido, la función de tales instituciones, se ha cifrado no sólo en la adecuación a la realidad nacional del discurso de la nueva derecha estadounidense, sino que de presentarlo a la sociedad salvadorena, como la única y mejor forma de ver la crisis y encontrarle la solución apropiada, alternativa que pretenden presentar como el deber ser del interés nacional, el cual a la vez también proponen, deberán de defender y tomar como sus propios intereses, todos los salvadoreños. También se debe tener presente que algunas de las instituciones de la derecha tradicional, en cierta forma han sido influenciadas y penetradas, por el discurso y los integrantes de la nueva derecha, de manera que esto se vuelve evidente en la medida que tales instituciones, hacen propio los planteamientos del nuevo actor.

En resumen, se puede decir que la nueva derecha, es el actor que en la escena nacional, ha captado la atención de todas las fuerzas politicas y sociales de la sociedad salvadorena, debido a que sus propuestas, en forma global las presenta utilizando hábilmente una forma de discurso eminentemente técnico-económico, aparentemente apolítico y sobretodo humanístico, que persigue el bienestar de la sociedad en conjunto, alejado de posiciones sectarias y dogmáticas, por medio de presentar ahternativas, que desde una visión económica de los hechos permitan al superarse la crisis del aparato productivo nacional, a través de las estrategias que proponen, facilitando en forma progresiva el crecimiento económico, de forma que tal crecimiento se vaya volcando en apuntar hacia favorecer a los sectores sociales más necesitados. Este planteamiento en sí, se infiere, ha captado la atención de todas las fuerzas político-sociales de la nación, por el tipo de respuesta, que han dado a las estrategias presentada, significando para los sectores modernizantes de la clase fundamental, el contenido de una actualización al interior del sistema. Los sectores sociales de ingresos medios y bajos, con poca cultura al respecto, contemplan el fenómeno con cierta indiferencia y preocupación. En lo que a los niveles académicos se refiere, recién se inicia un intento de análisis del mismo. Este estudio, con las limitaciones de la realidad en que se enmarca, pretende ser una contribución que ayude al conocimiento de dicho actor, para poder evaluar en forma objetiva sus propuestas, como sus acciones. Pues actualmente las expectativas que ha generado su oferta de solución, la interpretan los sectores sociales aliados de la nueva derecha, como una manera a través de la cual se garantiza la supervivencia del sistema. El 
sector social laboral, en sus primeras manifestaciones, ha expresado temor a que tal solución, conduzca a un deterioro mayor de las actuales condiciones de vida $y_{1}$ a nivel de los círculos académicos criticos del sistema, sus primeros pronunciamientos van desde el orden del escepticismo prudente, hasta el rechazo total, por considerarlo como una estrategia que tiende a la prolongación de la actual injusticia y violencia estructurales.

Veamos a continuación las organizaciones por medio de las cuales se materializa la nueva derecha y le sirven para expresar su proyecto a nivel económico, político, social e ideológico a la sociedad salvadorefna.

En el orden del contenido del discurso, por predominar en los aspectos de tipo económico, estas instituciones son:

FUSADES-Fundación Salvadorefia para el Desarrollo Económico y Social.

UDES-Unión de Dirigentes de Empresa Salvadoreña.

Grupo Promotor de la Bolsa de Valores de El Salvador.

Empresarios Juveniles.

A nivel social, existen instituciones como:

FUNDASALVA-Fundación Antidrogas de EI Salvador.

En el orden ideológico-religioso, existen instituciones como:

Hombres de Negocio del Evangelio Completo.

Asociación de Mujeres de Desayunos Católicos.

En este grupo de instituciones tenemos que agregar numerosas sectas cristianas protestantes, que han proligerado en las dos últimas décadas, las cuales guardan un denominador común: todas tienen sus centrales en E.U.A. siempre existen en su personal de alta jerarquia y misioneros más de algún ciudadano estadounidense, y las operaciones de las filiales salvadorefias, son financiadas en su mayor parte con fondos provenientes de las centrales. En este grupo también se incluye a los mormones-Iglesias de los Santos de los Ultimos Días.

En lo que se refiere a instituciones en el campo educativo, existen las siguientes como:

FEPADES-Fundación Empresarial para el Desarrollo Educativo.

Dentro de cada grupo de instituciones sehaladas, por la actividad que efectúan, cabe sefialar que la consistencia y coherencia de su discurso, les confiere unos mayores niveles de seriedad y credibilidad, 
situación que, en alguna medida, es reconocida por el resto de organizaciones y por la misma nueva derecha en conjunto. Es asi como a nivel de las organizaciones de tipo económico, FUSADES, es la que goza de más prestigio, en parte debido a una mejor estructura organizativa interna, obtenida como una consecuencia de gozar de un adecuado y amplio financiamiento, que es dado por la empresa privada industrial y fondos otorgados, en donativos y préstamos provenientes del AID. El resto de las instituciones de este grupo, en alguna medida aceptan dicha hegemonía ejercida por FUSADES, manifestándose esto, en la colaboración que reciben para efectuar sus actividades y el apoyo intelectual de dicha institución.

En lo que se refiere a las instituciones de carácter social, la que se menciona es de reciente constitución a esta fecha. Octubre de 1989. Sin embargo, se puede inferir de sus pocas expresiones que su esfuerzo se orientará por la recuperación de una moralidad, en cuyos valores se ha dejado de insistir en la práctica.

Respecto a las instituciones de carácter ideológico-religioso, el denominador común que las identifica radica en que divulgan una interpretación literal del discurso biblico; en otros términos, se pueden catalogar como sectas cristianas fundamentalistas, que en su actividad promueven entre su feligresía la aceptación de todo un esquema conformista sustentado en la humildad, pobreza y sumisión, valores que sirven de base para promover la aceptación del statu quo. En el mismo orden reiteran que la práctica de estos valores, profesados en vida por el fundador mitológico del cristianismo, permitirá gozar de la vida eterna a los creyentes fieles. Por contrario sensu, toda persona o fuerza social, que no sea fiel a tal prédica representa los maléficos designios de Satanás. Esta interpretación social de la religión, llevada al plano de la confrontación política, le permite a la nueva derecha, descalificar a sus opositores del sector laboral y a las fuerzas políticas que los representan, al identificarlas con el comunismo, porque esta doctrina no acepta las enseñanzas de Cristo, como normas valederas de patrón de conducta social.

Referente a las instituciones de carácter educativo, las sefialadas persiguen la formación de los cuadros técnicos, capaces de impulsar e implementar el proyecto de dicha fuerza, a nivel económico, político, social e ideológico. Estas instituciones financian sus actividades con fondos provinentes de sus actividades propias de empresas educativas, donativos de la empresa privada y préstamos y donativos del AID.

Lo expuesto recoge en forma resumida, las funciones específicas a nivel muy general de las instituciones de la nueva derecha en el país; 
sin embargo, estas funciones son orientadas por un marco conceptual de objetivos generales, a partir del cual, esta fuerza orienta su praxis, objetivos que se resumen en:

1. Incremento de la oportunidad y autonomia de los empresarios.

2. Disminución de la intervención del Estado en la economía.

3. Economía regida por las leyes del mercado.

Con la finalidad de ir perfilando el modelo que dicho actor propone a la sociedad, pasemos a ver la interpretación que efectúa de cada uno de los objetivos globales que se propone alcanzar.

En lo que se refiere al incremento de la autonomía de los empresarios, aqui está haciendo alusión a la libertad que debe disponer el sector productivo, referido a las decisiones de inversión y acción, actividades que deben de enmarcarse en un esquema que persigue la defensa del capital genérico. Situación que no descarta el sacrificio de los miembros ultraconservadores del sector privado, quienes con su actitud ponen en peligro la existencia y la reproducción del capital. A nivel ideológico, tal posición de autonomía se expresa en la publicidad que efectúan con la finalidad de obtener legitimidad de los sectores sociales populares, que están siendo afectados con la ejecución de las medidas de dicho proyecto, publicidad que se da a conocer, por medio de la radio, T.V., prensa y carteles en la vía pública, en los cuales se expresan frases como las siguientes: "El progreso del empresario salvadoreño es el progreso de todos los salvadoreños"t y "Libre empresa, libertad para progresar todo lo que quieras". 2 Promoción que se enmarca en el propósito de hacer aparecer el interés económico particular de la nueva derecha, como si fuera el interés general de la sociedad en este orden, lo mismo que encubrir las relaciones sociales de producción, cuyo éxito estriba en la obtención de una tasa cada vez mayor de plusvalia.

Referente al objetivo de una disminución de la intervención del estado en la economía, esto debe considerarse como que el estado no debe generar una actividad productiva de bienes y servicios en competencia con el sector empresarial. Haciendo alusión implicita a las empresas textileras, camaroneras, ingenios azucareros y hoteles que maneja la Corporación Salvadoreña de Inversiones -CORSAIN; así como también al control administrativo que ejerce la CEL, sobre las empresas distribuidoras de energia eléctrica nacionalizadas.

En el mismo orden, también se debe considerar la privatización de ciertos servicios que presta el estado, los que por las características de 
monopolios naturales, garantizan una atta rentabilidad al inversionista privado, tal sería el caso de los servicios telefónicos y de distribución de energía eléctrica. También en este objetivo se sustenta toda la argumentación que se expresa en relación a la disminución del tamaño del aparato estatal, cuya tinalidad sería que la empresa privada llegue a prestar los más variados servicios, incluso aquellos relacionados con la seguridad social. En otros términos, bajo los lineamientos de este esquema, el estado progresivamente tendería a reducir sus funciones a la administración de justicia, seguridad, orden y todas aquellas funciones, que no ofrecen atractivas ganancias a los inversionistas privados.

Respecto al aparato productivo, regido por las leyes del mercado, esto se puede ver desde varias perspectivas, una de ellas es que toda la producción de bienes y servicios, estará orientada a la satisfacción de preferencias personales de aquellos sectores de la sociedad con alta capacidad de consumo. En otros términos, implicitamente se excluye con este mecanismo, la satisfacción de las necesidades sociales, es decir, las básicas de la población con bajos niveles de ingreso y limitada capacidad de consumo. Otra perspectiva de ver esto, apunta en el sentido de que la producción e intercambio de mercancias, incluyendo la fuerza laboral, sus precios serán determinados por el libre juego de la oferta y demanda en el mercado.

En resumen, lograr la realización de estos tres objetivos, para la nueva derecha, signiticará en la práctica alcanzar la hegemonia y la supeditación del estado a los intereses privados; en otros términos: la subordinación del poder político estatal al poder económico privado y especificamente al representado por la nueva derecha.

\section{MODELO DE HEGEMONIA}

La nueva derecha es un actor político-social, que considera su origen y praxis, como una consecuencia directa, resultante de una crisis de conducción del sistema. En otros términos, se puede decir provocada por una inadecuada dirección y, no por una crisis del capitalismo mismo. Proceso que se fue gestando lentamente, cuando el actor que ejerció la hegemonia, —derecha tradicionat- llegó a considerar, que el modelo económico y político-social, por medio de los cuales condujo el bloque histórico salvadoreno por cerca de un siglo, pedia funcionar sin mayores modificaciones indefinidamente; es decir, un modelo que cuando aceptó la introducción de algunas modificaciones, con la iinalidad de modernizarse, to hizo con reticencia, atraso y poca voluntad; consiguientemente al incorporar dichas nuevas formas, to hizo con tanta demora, que en ese momento ya habian sido superado por el desarrollo 
de la ciencia y la tecnología. Esto se explica por el proteccionismo que brindó el estado al sector privado, cosa que a la derecha tradicional le permitió valorizar el capital, pero dialécticamente provocó su atraso tecnológico, por la prolongada duración de tal proteccionismo. Manteniéndose por ese hecho siempre en forma obsoleta, a pesar del amplio cuestionamiento que recibió en diferentes coyunturas, los cuales provinieron de diferentes sectores de la sociedad, cuestionamientos que en la medida que se presentaron con mayor frecuencia y por consiguiente, a menores plazos fueron generando las condiciones económicas, sociales, políticas e ideológicas, que progresivamente provocaron una polarización de la sociedad, que se expresó asi; por un lado, los sectores sociales de attos ingresos, defensores del modelo de la derecha tradicional, en razón de ser los mayores beneficiarios, de tal forma de hegemonia; en el lado opuesto, los sectores sociales de bajos ingresos, que cuestionaron repetidamente al sistema, por ser los más perjudicados por la forma como se ejerció el gobierno y se dirigió el aparato productivo. En este marco creciente de polarización de la sociedad salvadoreña, definido por la existencia de una crisis de las instancias del estado, que se vino gestando en razón de la posición intransigente del actor empecinado en sostener inalterablemente un modelo de hegemonia, que se había vuelto obsoleto a raíz de no ser actualizado en consonancia al desarrollo social alcanzado, por una parte; por otra, como consecuencia del fuerte cuestionamiento, expresado en contra de tal forma de hegemonía, por los sectores sociales de ingresos medios y bajos, a quienes les tocó soportar el impacto negativo de tal modelo que se expresó empíricamente por medio de un deterioro de las condiciones de vida del sector laboral que para fines de la década de los años setenta, se manifestó en cifras como:

- Desnutrición en nińos menores de 5 años: $74.5 \%$.

- Población sin capacidad de pago para gasto médicos y medicinas: $85.0 \%{ }^{3}$

- Analfabetismo global de la población: $63.7 \% .^{4}$

- Población que habitó en las zonas marginales del área metropolitana: $392,453 .^{5}$

Sólo para mencionar, las cifras más significativas, que presentan las condiciones infrahumanas, en que vivía a fines de tal década la gran mayoria de salvadoreños.

En este marco referencial de crisis descrito, la nueva derecha aparece en la escena nacional, como un actor que por su discurso y acciones, se presenta como una fuerza modernizantes, progresista, ${ }^{B}$ 
que trata de capitalizar para su beneficio, los errores de la derecha tradicional; además de crear para sí misma a la vez, la imagen de ser la única fuerza político-social, capaz de presentar un nuevo modelo de hegemonia económico y político-social, coherente con las limitaciones de la realidad nacional, los que a la vez perseguirán corregir en alguna medida los errores del pasado, proyectando la imagen de ser los únicos capaces de formular e implementar una nueva estrategia, que permita dar inicio a un proceso, que progresivamente conduzca al desarrollo económico, político y social del estado salvadorefio. Tales modelos de conducción del estado, no sólo facilitará superar la falta de adecuada dirección, sino que en alguna manera se convertirá en la mejor forma de defender al sistema.

El marco teórico al interior del cual se desarrollan, el modelo de gobierno a nivel económico y político-social que proponen, descansa en dos postulados.

\section{Neoliberalismo.}

\section{Neoconservadorismo.}

Pasemos a ver qué es lo que se debe interpretar, por cada uno de estos postulados. En lo que se refiere al neoliberalismo, debemos de partir del hecho de que las categorias económicas que manejan son las propias de la doctrina económica liberal, pero éstas han pasado por un proceso de cambio, modificaciones y actualizaciones, que les permite estar en consonancia y ser coherentes, con el desarrollo que ha experimentado el capitalismo, los avances de la ciencia, incluso los de la última revolución industrial, y su aplicación en la práctica -tecnología- Consiguientemente, por esa reelaboración constante de las categorias económicas, sin abandonar el marco liberal que les dio origen, en la tendencia de mantenerse vigentes, sin llegar a atrasarse y volverse obsoletas es que se deben catalogar como neoliberales. En tal sentido, un ejemplo que ilustra ampliamente lo anterior, es que actualmente algunos miembros del sector productivo privado nacional a nivel agropecuario, están utilizando técnicas de inseminación artificial y semillas mejoradas, con la finalidad de incrementar la eficiencia, productividad, producción y rentabilidad de sus empresas agrícolas. Lo anterior constituye un caso de aplicación de los adelantos en genética obtenidos por medio de la biotecnología.

Respecto a lo que se debe de interpretar por neoconservadorismo, se puede sostener que está referido con un mayor predominio a la dimensión política del postulado, en tal sentido, su lectura presente va en la tendencia del mantenimiento del sistema capitalista, las estruc- 
turas económicas, políticas y sociales, generadas por el mismo, asi como también la injusticia y violencia estructural. Lo novedoso en este nivel es que se utiliza un discurso, cuya retórica hace énfasis en la necesidad de un desarrollo de "instituciones democráticas", "sindicalismo libre", "respeto a los derechos de las personas", "regímenes surgidos de elecciones libres", etc., etc...

Títulos que suenan bien a nivel publicitario, creíbles sólo para los ingenuos $e$ incautos, pero que en el fondo pretenden encubrir los atributos de un capitalismo dependiente subdesarrollado, cuya rentabilidad para la nueva derecha se fundamenta en el irrespeto a los derechos económicos, políticos, sociales y humanos, de la inmensa mayoria. Específicamente hablando para el caso de El Salvador, esto se plantea asi, en función del patrón de conducta que históricamente ha orientado las acciones de la clase fundamental. En el mismo orden, otra razón que induce a percibir una realidad no favorable a los intereses del sector laboral a pesar de la retórica del discurso de la nueva derecha, en dicho sentido, es la implementación de algunas medidas de su programa económico, puestas en vigencia en julio próximo pasado, to cual ha generado un incremento de la inflación y contracción del empleo a nivel gubernamental. ${ }^{8}$

En este marco referencial de neoliberalismo y neoconservadorismo, pasemos a ver con mayor especificidad los modelos de hegemonía a nivel económico y político-social que propone con los cuales pretende desplazar a la derecha tradicional, de su posición de hegemonia, o al menos persuadirla que tome sus ideas y las ejecute en la práctica como propias.

\subsection{Modelo de hegemonía a nivel económico}

El objetivo que se propone alcanzar la nueva derecha, expuestos al inicio de este capitulo, desplazar como tracción hegemónica del bloque en el poder a la derecha tradicional, se enmarcan en una concepción neoliberal económica, expresándose empíricamente en un conjunto de principios, cuyo contenido manifestado en la realidad, convierten a esta fuerza en un actor dinámico, progresista, modernizante, de avanzada y futurista. Atributos que en su conjunto se orientan en la tendencia de construir un aparato productivo, el cual en alguna medida tenderá en el mediano y largo plazo a generar condiciones para el desarrollo de las fuerzas productivas, en un marco inicial de crecimiento que posteriormente conducirá a un desarrollo económico, como forma óptima y única de resolver en el futuro los graves problemas sociales, políticos e ideológicos, que actualmente polarizan a la sociedad y originan en parte 
el conflicto político-social, como máxima expresión de la crisis que erosiona las diversas actividades, tanto de la sociedad política como de la civil. En este conjunto de juicios, que denotan un análisis y propuesta de solución economicista neoliberal; veamos cuáles son los principios que orientaran la praxis de la nueva derecha y que constituyen la esencia del modelo de hegemonía económico que proponen:
1. Realismo.
2. Pragmatismo.
3. Eficiencia.
4. Productividad.
5. Rentabilidad'.

Respecto a la interpretación que efectúa sobre el realismo, los ubica inicialmente en el sentido de argumentar, responsabilizando a la intervención del estado en la economia, como el factor que genera condiciones artificiales, tendientes a favorecer a determinados agentes oconómicos, situación que condujo a desnaturalizar al mercado, en la medida que entorpeció la libre expresión de las fuerzas del mismo ${ }^{10}$, las cuales sólo deben ser regidas en su expresión por la ley de la oferta y la demanda. En este sentido, disposiciones estatales tendientes a orientar las inversiones por medio de mecanismos de proteccionsmo, incentivos, control de precios, etc., etc... generaron condiciones que bloquearon los estímulos del mercado a los productores eficientes; en contrario sensu, tal conducta del estado terminó por premiar a productores ineficientes, situación que en el mediano plazo, permitió la creación de un aparato productivo, ineficiente, con baja productividad, obsoleto y con casi nulas posibilidades competitivas en el exterior.

En este marco de un aparato productivo ineficiente, que produce apoyándose en la protección estatal, el realismo o ser realista implica para la nueva derecha, dejar en el pasado las perturbaciones que ocasiona la injerencia del estado en la economía, por medio de las medidas señaladas, aunque ello conlleve al sacrificio de algunos productores. Pero en realidad lo que se persigue es defender el capital genérico, en otros términos al sistema capitalista y no a capitalistas en particular; en tal sentido la nueva derecha propone una serie de medidas, que se deben expresar por medio de políticas, que corresponderan al estado su ejecución, en el entendido que este deberá asumir el papel de actor promotor y facilitador del desarrollo."

En este marco de realismo, tales medidas deberán compender: 1) Liberalización del mercado, que abaracará disposiciones tendientes ha la eliminación de controles de precios tanto de productos como de servicios, generados por el sector privado, to que de acuerdo con el 
esquema y modelo que proponen, afirman que en el mediano plazo favorecerá al consumidor, debido a que le proporcionara servicios y productos de mayor calidad y durabilidad. 2) También se dejan sin efectos los controles de precios sobre los productos, se deberá liberalizar también el mercado financiero, meta que comprenderá un proceso de varias etapas, que para el caso especifico del pals se resumen en lo siguiente: a) Tasa de interés real o positiva, debiendo interpretarse esto en el sentido de una tasa de interés del sistema financiero crediticio, tanto para los ahorros como para los créditos, superior o mayor a la inflación, medida que estimulará el ahorro, permitiendo una mayor captación del mismo al sistema financiero, $b$ que en el mediano plazo se expresará por medio de una mayor disponibilidad de recursos monetarios, que se podrán destinar a nuevos proyectos de inversión rentables. Especificamente aquellos destinados a la producción para la exportación. b) El conflicto que sutre el país desde el inicio de la presente década, ha golpeado fuertemente al sector productivo, fenómeno que en alguna medida se manifiesta por la mora de éste con el sistema bancario, en tal sentido se vuelve necesario efectuar un saneamiento de tal mora, por dos razones fundamentales, una para evitar la descapitalización de la banca y con la finalidad de volverla eficiente, tanto en la función de captación de recursos financieros como en la asignación de los mismos, por to que se hace necesario regresar el sistema bancario al sector privado. c) En un último momento del proceso, se deberá constituir el mercado de capitales, el cual empiricamente se expresará por la existencia de una "bolsa de valores", que no sólo tenderá a generar una modernización del capital, sino que a la vez será el máximo organismo rector del aparato productivo, ya que su función esencial consistirá en que toda la actividad productiva esté firmemente regida por las leyes del mercado, fenómeno que implicará la salida del mismo de las unidades productivas no eficientes. En otros términos, la privatización del sistema bancario crediticio y la creación de un mercado de valores, agilizarán la asignación de recursos monetarios a los productores eficientes, sin dilación y trámites engorros, en una última instancia el mercado de valores, minimizará las políticas restrictivas del Banco Central y será un recurso al servicio del sector productivo eficiente. ${ }^{12}$

En el extremo caso que no se pudiera concretar la creación del mercado de valores, la intermediación tinanciera, tendrá que tomar una conducta ágil y dinámica, orientando la asignación de recursos en forma eficiente, en el sentido esírictamente de la dimensión económica del término. ${ }^{13}$

3) La puesta en práctica de las medidas de liberalización de los 
precios de los productos, servicios y del capital, implícitamente está expresando la necesidad de establecer una paridad real del colón con respecto al dólar, la razón de esto, se enmarca en el objetivo de terminar con los factores que han estado generando una situación artilicial que presenta un aparato productivo fuerte y una economía sana, situación totalmente alejada de la realidad, que ha estado encubriendo graves desequilibrios macroeconómicos, tanto a nivel interno como externo, cuyas expresiones empíricas se han manifestado por medio de creciente desempleo, déficit fiscal, déficit con el sector externo e inflación que se puede apreciar con más detenimiento en las cifras del siguiente cuadro:

En tal sentido, el establecimiento de la paridad real de nuestra mo-

\begin{tabular}{|c|c|c|l|}
\hline Año & $\begin{array}{l}\text { (1) Déficit } \\
\text { (2) Comerclal }\end{array}$ & $\begin{array}{l}\text { (1) Déficlt } \\
\text { (3) Fiscal }\end{array}$ & $\begin{array}{l}\text { Inflación } \\
\text { (2) \% }\end{array}$ \\
\hline 1979 & 230,590 & $-242,360$ & 14.8 \\
1980 & 279,680 & $-608,643$ & 18.6 \\
1981 & $-484,770$ & $-813,292$ & 14.9 \\
1982 & $-447,200$ & $-841,387$ & 11.7 \\
1983 & $-134,900$ & $-531,963$ & 13.1 \\
1984 & $-251,600$ & $-468,021$ & 11.7 \\
1985 & $-260,200$ & $-241,508$ & 22.3 \\
1986 & $-180,000$ & $-345,646$ & 31.9 \\
1987 & $-403,100$ & $-470,768$ & 25.0 \\
1988 & & $-638,759$ & \\
\hline
\end{tabular}

FUENTE:

(2) Mernoria del Banco Central de Reserva. Años 1984, 1986, 1987 y 1988.

(3) Francisco Lazo Marin: Monto del délicit fiscal y su financiamiento. Estudio no publicado aun.

(1) En miles de colones.

neda, tenderá a generar un efecto de saneamiento de la economia, en razón de que en principio los productos de exportación se volverán más competitivos por su bajo precio, lo que permitirá incrementar las exportaciones, con el consiguiente beneficio en el doble sentido de mayor captación de divisas y disminución del déficit de la balanza comercial. ${ }^{14}$

4) El realismo que propone esta fuerza se debe de practicar, también incluye reconocer el efecto perturbador y dañino que ha provocado a la economia el mantenimiento de unidades productivas de bienes y servicios, cuya producción y rentabilidad ha estado en función directa dependiendo de niveles de proteccionismo, subsidios e incentivos fiscales. Esto ha generado la existencia de unidades y ramas de la 
producción, ineficientes, de baja producción y productividad, en cuanto se refiere a volumen y calidad, sin ninguna capacidad competitiva en el exterior y que en la práctica han venido funcionando con mucha dependencia del estado. En otros términos, se podrian considerar como industrias parásitas, que han absorbido cuantiosos recursos económico del sector público. Consiguientemente se impone la necesidad de sanear el aparato productivo, mediante la derogatoria inmediata de las leyes proteccionistas de la industria, los incentivos fiscales, los subsidios y cualquier otra disposición vigente en tal sentido. En resumen, una unidad productora de bienes y/o servicios, su existencia en el mercado será determinada por su capacidad de competir, en igualdad de condiciones con el resto de unidades productivas. En el mediano y largo plazo esto generará la existencia de un sistema económico eficiente. ${ }^{15}$

5) De lo expuesto anteriormente, se puede abstraer que la tendencia dominante en el modelo, radica en que la determinación de los precios de los factores productivos, deberá ser una consecuencia directa del libre juego de la oferta y demanda. En este marco se vuelve contradictorio la fijación por el estado de salarios mínimos para la industria, el comercio y la agricultura, pues esto lo único que ha generado son niveles de ineficiencia en la fuerza laboral, consiguientemente tendrá que desaparecer tal práctica de fijación de salarios y el precio de la fuerza laboral deberá ser establecido en función de la oferta y demanda de fuerza de trabajo en el mercado laboral.

En resumen, se puede decir que la interpretación que la nueva derecha efectúa sobre el principio del realismo, por medio de perseguir la fijación de los precios de los factores productivos, bienes y servicios, en función del libre juego de la oferta y demanda, pretendiendo alcanzar la existencia de un sistema económico eficiente, trata de encubrir la esencia de su objetivo, que radica en la obtención de mayores niveles de rentabilidad de sus inversiones, esto en la práctica se presentará de la siguiente manera: en lo que se refiere a la liberalización de los precios de productos y servicios, se debe tener en cuenta que no por aumentar los precios, aquellos mejorarán en calidad, sobretodo si juzgamos en atención al patrón de conducta empresarial, que se enmarca en un afán desmedido por las ganancias, consiguientemente el consumidor terminará por pagar un precio mayor por los mismos productos y servicios de antes.

Referente a la fijación de una tasa de interés real, tanto para el ahorro como para el crédito, la nueva derecha da por hecho la privatización del sistema bancario y crediticio, situación que si juzgamos en sus consecuencias nos encontramos con los siguientes hechos, los 
sectores sociales de ingresos medios y bajos carecen de capacidad de ahorro actualmente, situación que se percibe se dramatizará en el futuro inmediato, al entrar a funcionar las medidas sefialadas. Por tanto, el ahorro continuará siendo un privilegio de los sectores sociales de altos ingresos, quiénes por este mecanismo transferirán recursos monetarios, para los proyectos de inversión de la nueva derecha, en otros términos bajo este esquema la nueva derecha aprovechará los recursos financieros ociosos de la derecha tradicional agroexportadora en dos sentidos para beneficio propio y como agente intermediaro financiero, de manera tal que ambas acciones le facilitarán obtener altas ganancias sin arriesgar recursos monetarios propios.

En cuanto a lo que corresponde a la fijación de una paridad real de la moneda nacional, esto no se puede juzgar separado del contexto del esquema de diversificación de las exportaciones, en este sentido, la devaluación del colón respecto al dólar, conlleva el fin implícito de otorgar una mayor cantidad de colones a los sectores exportadores, es decir, tal sector social gozará de una mayor disponibilidad monetaria por sus exportaciones. Ingenuamente lo que no ha previsto la nueva derecha, o si to ha visto, ha sido no en su justa dimensión es que todas las importaciones se encarecerán en igual proporción a la devaluación del colón, consiguientemente por el carácter trunco del aparato productivo salvadoreno, esa mayor liquidez se fugará al exterior y en el mediano plazo agravará el déficit de la balanza de pagos. Es natural que, tanto la nueva derecha como la derecha tradicional, al sentir el impacto negativo de la devaluación, terminarán por recurrir en transferir el incremento de los costos de la producción al consumidor nacional, las consecuencias inflacionarias de esto como su repercusión a nivel social, se manifestarán empíricamente en un deterioro creciente de la calidad de vida de los sectores sociales asalariados en el corto plazo, en el mediano y largo plazo agudizarán el conflicto social existente.

Deterioro que ha sido evidente en las dos últimas décadas, que se puede apreciar en el cuadro siguiente; debido al incremento del costo de la vida por la inflación.

En relación a la fijación del salario en función de la oferta y demanda de trabajo en el mercado laboral, se debe partir del hecho real del alto desempleo de la PEA a nivel unbano y rural, cosa que repercutirá negativamente sobre el sector laboral al generar una contracción nominal del salario, dramatizando el real existente del mismo generada por la inflación. Por el contrario, quien gozará el beneficio de esta medida será el sector productivo al bajar los costos de la fuerza de trabajo, cosa que le facilitará la obtención de mayores niveles de ganancia. 
Famllias bajo la línea de pobreza e Indlgencla por área geográflca. Años 1977-1985

\begin{tabular}{|l|c|c|c|c|}
\hline & \multicolumn{2}{|c|}{1977} & \multicolumn{2}{c|}{1985} \\
\cline { 2 - 5 } & $\begin{array}{l}\text { Valores } \\
\text { absoluto }\end{array}$ & $\begin{array}{l}\text { Prop. en } \\
\text { relaclón } \\
\text { a su total }\end{array}$ & $\begin{array}{c}\text { Valores } \\
\text { absolutos }\end{array}$ & Porcenta]e \\
\hline $\begin{array}{l}\text { Línea de pobreza: } \\
\text { Costo de la canasta } \\
\text { básica }\end{array}$ & 4395.40 & & $1,207.35$ & \\
\hline $\begin{array}{l}\text { Familias afectadas } \\
\text { a nivel nacional }\end{array}$ & $547,382.00$ & $71.4 \%$ & $828,694.00$ & $87.5 \%$ \\
\hline $\begin{array}{l}\text { Familias afectadas } \\
\text { a nivel metropolitano }\end{array}$ & $44,556.00$ & $30 \%$ & $166,747.00$ & $70 \%$ \\
\hline $\begin{array}{l}\text { Familias afectadas } \\
\text { a nivel urbano }\end{array}$ & $177,348.00$ & $50 \%$ & $400,168.00$ & $80 \%$ \\
\hline $\begin{array}{l}\text { Familias afectadas } \\
\text { a nivel rural }\end{array}$ & $370,034.00$ & $90 \%$ & $428,526.00$ & $96 \%$ \\
\hline
\end{tabular}

\begin{tabular}{|l|r|r|r|r|}
\hline $\begin{array}{l}\text { Línea de pobreza } \\
\text { absoluta: } \\
\text { Costo de la canasta } \\
\text { de alimentos }\end{array}$ & $\$ 197.70$ & & & \\
\hline $\begin{array}{l}\text { Familias afectadas } \\
\text { a nivel nacional }\end{array}$ & $235,428.00$ & $30 \%$ & $607,209.00$ & $64 \%$ \\
\hline $\begin{array}{l}\text { Familias afectadas } \\
\text { a nivel metropolitano }\end{array}$ & $14,664.00$ & $10 \%$ & $95,284.00$ & $40 \%$ \\
\hline $\begin{array}{l}\text { Familias afectadas } \\
\text { a nivel urbano }\end{array}$ & $70,932.00$ & $20 \%$ & $250,105.00$ & $50 \%$ \\
\hline $\begin{array}{l}\text { Familias afectadas } \\
\text { a nivel rural }\end{array}$ & $164,496.00$ & $40 \%$ & $357,104.00$ & $80 \%$ \\
\hline
\end{tabular}

FUENTE Cuadernos de Investigacón, Centro de Investigaciones Tecnológicas y Ciénificas, CENITEC, N 1, Año 1.

Febrero de 1989. San Salvador, El Salvador, Pág. № 12.

En relación a la interpretación que la nueva derecha, efectúa sobre el pragmatismo, lo hace en varias formas de lectura del mismo, una de ellas estriba en sostener enfáticamente que no pueden existir soluciones universales o globalizantes, esto en otros términos lo ve en el sentido de que cada realidad social que presenta problemas, conflictos y crisis 
especificas, amerita medidas de solución específicas también, en tal marco referencial, las attemativas de solución que funcionan o funcionaron para resolver una crisis en una determinada realidad históricaconcreta, no funcionarán o lo harán defectuosamente en otra sociedad, aunque la crisis que se pretende resolver tenga algunos niveles de similitud, en su origen y manifestación fenomenológica. Otra lectura que hace en relación al pragmatismo, es que no toma identificación con actor político determinado, sino que brinda circunstancialmente apoyo, a la fuerza política que toma como propia sus propuestas, en este sentido se puede decir, que la nueva derecha está convencida de que no tiene aliados ni adversarios, sólo tiene y defiende intereses. Esto último en si viene a convertirse en una manera de explicación de su surgimiento como fuerza en el escenario nacional, a la vez también sirve para explicarse la retórica economicista de su discurso, situación con la que pretende sostener una aparente neutralidad política, con la finalidad de encubrir su punto de vista y posición de clase fundamental, tratando de ubicar el contenido de su discurso en niveles eminentemente técnicos.

En honor a la verdad, se puede sostener que el discurso que expresa la nueva derecha salvadorefia como propio, no supera el nivel de la adecuadción del expresado por su homóloga estadounidense. También en este sentido pretende calcar al caßón, como el "deber ser" del sistema económico salvadorefio, los ejemplos de funcionamiento de la economia de Chile, bajo el régimen de Pinochet, Corea del Sur y Formosa, regimenes todos a los que políticamente no se les puede calificar como democráticos y cuyos aparatos productivos están controlados por intereses económicos de grandes consorcios transnacionales.

En cuanto se refiere al principio de eficiencia, éste to cita en repetidas ocasiones en su discurso y pide su observación tanto del sector público como del privado; en relación al primero, llega a considerar que el aparato estatal ha llegado a crecer en una proporción mayor a sus funciones, habiéndose separado a la vez de sus verdaderas atribuciones, esto ha generado la existencia y mantenimiento de una burocracia estatal, la cual en la medida que crece, cae en rendimientos decrecientes. En tal sentido, se impone en el corto plazo, por el estado, emprender acciones definidas en el marco de reducir el tamaño del aparato del sector público a sus verdaderas funciones, universalmente reconocidas en una economia regida por las leyes del mercado, las cuales se reducen a: velar por la seguridad de los habitantes, mantener el orden público, administrar justicia y hacer que se respete el derecho a la propiedad, lo mismo que prestar servicios que por su naturaleza son incompatibles con los principios que orienta y al sector privado, así como también velar por la soberania e integridad del territorio na- 
cional. ${ }^{16}$ En otros términos el estado al reducir el tamafio de su aparato, to podrá efectuar por dos vías, una que consiste en la privatización de algunas de sus dependencias, que actualmente funcionan generando niveles de competencia con la empresa privada. Otra forma será por medio de clausurar dependencias cuyas funciones pueden ser absorbidas por otras oficinas estatales, sin menoscabo de su cumplimiento; esta forma de proceder permitirá que el estado recupere la eficiencia y que a la vez reduzca substancialmente los costos de funcionamiento, 10 cual unido a otras políticas tendientes a racionalizar el gasto público, facilitarán en el corto y mediano plazo una reducción del déficit del gasto público, a quien la nueva derecha considera como principal factor inflacionario, desequilibrio macroeconómico que se verá más adelante.

En lo que se refiere a la eficiencia que debe ser observada por el sector productivo, la nueva derecha lo identifica con un proceso continuo de incorporación a la producción los avances de la ciencia y su aplicación concretada en la tecnologia. Este proceso continuo de modernización de la línea de montaje de las diferentes unidades productivas, como de su producción, facilitará que por medio de nuevos coeficientes técnicos de producción, se logre una disminución de los costos de la misma, aspectos que permitirá un incremento de la rentabilidad, por una disminución de costos. También la modernización de la línea de montaje, permitirá la obtención de un incremento de la productividad, situación que en el corto y mediano plazo se traducirá en un aumento global de la producción. Consiguientemente la obtención de unos mayores niveles de eficiencia, a través de la modernización del sistema productivo, con el subsecuente efecto de incremento en la productividad y producción, permitirá a la industria nacional, generar unas condiciones favorables para competir tanto en el mercado internacional como en el nacional; es decir que la nueva derecha interpreta que la eficiencia y la competencia están íntimamente relacionadas y no existe una separada de la otra, en un mercado regido por la ley de la oferta y la demanda. ${ }^{17}$

Lo cierto es que la eficiencia que se le pide observar al estado en función de una disminución del tamaño del aparato estatal, en la práctica va a generar un incremento del desempleo, situación que en el marco de la actual coyuntura, no permitirá que se presenten nuevas oportunidades de ocupación a los afectados, posiblemente ni en el mediano plazo, hecho que empiricamente en el corto plazo se traducirá inicialmente en un deterioro de la calidad de vida de los grupos familiares afectados y en la medida que se prolongue la desocupación de tal grupo social, tenderá a que se produzca un deslizamiento de dicha población hacia mayores niveles de pobreza. La consecuencia 
inmediata de este fenómeno, se expresará por medio de un agravamiento del conflicto social o en mayor emigración.

La eficiencia que la nueva derecha propone para el sector productivo, está en función de una mayor rentabilidad, obtenida por medio de una disminución de los costos de producción, a través de mecanismos que permitan la extracción de una plusvalia, tanto relativa como absoluta. En otros términos la eficiencia encubre el propósito de la nueva derecha, de apropiarse de una proporción cada vez mayor del excedente económico generado en la producción, en tal sentido, es de esperar una mayor pauperización del sector laboral. Las consecuencias de esto a nivel social, se expresarán por medio de unas mayores desigualdades, las cuales contribuirán a incrementar el conflicto políticomilitar existente. En tal marco de intereses que estimulan a la nueva derecha a plantear tales propuestas de solución a la crisis económica y al conflicto politico-militar, da la impresión, al menos personalmente, de que no trata de perseguir solución a to uno ni a lo otro, por contrario sensu, el modelo de hegernonia que propone en el orden económico, persigue el claro objetivo de hacer prevalecer en forma dominante la estructura concentrada de la riqueza y del ingreso, muy a pesar de todo to que exprese en su discurso, quedando el contenido de éste en el nivel de retórica, lo que no logra persuadir y convencer a los sectores sociales de ingresos bajos y medios organizados y mucho menos obtener legitimidad de tal sector de la población.

Respecto a cómo debe ser la oferta monetaria, la nueva derecha propone sin llegar a mayores niveles de elaboración, que la oferta monetaria debe crecer en igual forma o proporción al crecimiento real de la economia; en otros términos, la oferta nominal monetaria deberá crecer a igual ritmo del crecimiento real del PIB. En tal sentido, el financiamiento neto al gasto público, se limitará a los márgenes razonables, permisibles en el condicionamiento anterior ${ }^{18}$ Esto se debe a dos razones: una que consiste en tratar de explicar que la inflación en el pals, se debe a la emisión monetaria inorgánica; la otra, pretende explicar que la inflación, radica en argumentar, que la masa monetaria inorgánica que recibe el estado, incrementa la demanda de bienes y servicios al sector privado, fenómeno que ante la oferta inelástica del aparato productivo, termina por generar inflación. Lo cierto es que la inflación en el país obedece tanto a causas intemas como externas, de manera que las primeras obedecen a factores como: la devaluación del colón. Otro elemento no menos importante que el anterior, es el incremento desmedido de los precios, efectuado por los comerciantes inescrupulosos, quienes ante las espectativas de iminentes devaluaciones, anticipan mayores márgenes de ganancias al incrementar los 
precios de bienes y servicios. Ultimamente otro factor que ha acelerado la inflación, ha sido la liberalización de los precios, sancionada por el gobierno, a partir del 26 de julio de 1989 pasado.

Entre las causas extemas de la inflación, tenemos la devaluación del dólar, lo cual ha generado un incremento de los precios de materias primas, insumos, bienes de capital y servicios, necesarios para mantener el funcionamiento del aparato productivo.

Otra causa externa de la inflación en el pais, se ubica en el aumento de precios de los hidrocarburos, inicialmente en la década de los años setenta. De to expuesto se puede abstraer, que la nueva derecha pretende encubrir, por medio de un discurso sustentado en una retórica sofista, las causas internas de la inflación provocadas por la conducta voraz de sus congéneres y base social de apoyo. En resumen, se puede sostener que las propuestas de esta fuerza, con la finalidad de hacer prevalecer su modelo económico, por medio del cual aspira a ejercer hegemonia, tienden hacia el establecimiento de una estrategia de crecimiento económico hacia afuera, el cual básicamente descansará en una diversificación de las exportaciones no tradicionales, asl como de los mercados. En este marco, implícitamente se debe comprender que las exportaciones tradicionales se tendrán que fortalecer y desarrollar las no tradicionales, especificamente las de origen agrícola, a expensas de cultivos que deberán satisfacer dos condiciones, la primera consistente en tener asegurado un buen mercado en E.U.A. y la segunda, ser irtensivas en fuerza de trabajo. En tal caso podrán ser productos como: melón, brócoli, espárragos, cardamomo, semilla de marañón. etc., etc... Esta producción permitirá a la vez cumplir con dos objetivos, los cuales son: generación de empleo a nivel agricola y una disminución del déficit de la balanza de pagos, por medio de haber crecido las expontaciones, objetivo que implícitamente conlleva un incremento en el ingreso de divisas al país. Este modelo económico de crecimiento hacia afuera, pone al descubierto el interés de la nueva derecha en mantener y consolidar un aumento en la dependencia económica de E.U.A., pues por parte del hecho de que tal país, se deberá constituir en el mejor mercado para la producción primaria sefialada. En tal sentido, se puede decir lo siguiente: actualmente la producción para la exportración que se apoya esencialmente en el café, con otros productos como camarón, azúcar de caña y algodón, todos de menor significado en este rubro, han generado una situación de extrema fragilidad de la economía. En tal sentido, una economia que dependerá de exportaciones de productos como los ya mencionados, es de esperar que presentará una mayor debilidad en el mercado internacional, pues si a las exportaciones tradicionales se les ha llegado a conocer como: 
"economía de sobremesa", a las exportaciones no tradicionales se le puede denominar, propias de una economía "dietética", en el sentido de no ser indispensables a la vida y utilizarse por su bajo contenido de calorias y propiedades cosméticas. En otro nivel, el modelo propuesto implicitamente rechaza toda estrategia tendiente a la formación de un mercado interno de consumidores. En tal orden, la interpretación económica social que se puede hacer de tal actitud, es que la nueva derecha pretende una revitalización del sistema capitalista salvadoreño, pero a la vez deberá continuar apoyándose fundamentalmente en una estructura concentrada de la riqueza y del ingreso, situación que empíricamente a nivel de la sociedad se manifestará por medio del mantenimiento y ampliación de las desigualdades sociales existentes al presente. Sin pretender entrar en el campo de la ciencia ficción y en base de las medidas puestas en práctica por el gobiemo, hasta el presente -octubre 1989- las cuales estan contempladas en las propuestas del modelo económico de la nueva derecha, todo parece indicar que la realidad tiende a confirmar la aseveración sobre la ampliación de las desigualdades, lo mismo que a la profundización y ampliación de la injusticia y violencia estructural, como corolario implícito, del modelo explicito de la nueva derecha, para ejercer la hegemonía económica en la sociedad salvadorefia.

\subsection{Modelo de hegemonía a nivel político-social}

El modelo que la nueva derecha, se propone ejecutar con la finalidad de ejercer la hegemonia, a nivel político-social y lograr la conducción del bloque histórico salvadoreño, lo percibe al interior de una concepción neoconservadora, estrategia que es necesario aclarar a fin de poder comprender la motivación que impulsa a dicha fuerza, así como los objetivos que se propone alcanzar, objetivos que no aparecen en forma explícita en el modelo, los cuales son encubiertos hábilmente, por medio de un conjunto de slogans, que se ocupan de hacer resaltar, la unidad indisoluble entre: "empresa privada, democracia y progreso", como la base única a partir de la cual se puede lograr el desartollo político y social, que beneficiará a la totalidad de la sociedad salvadorefia. Históricamente la derecha tradicional se ha ocupado de probar la falta de veracidad de tal afirmación, actualmente la nueva derecha se propone con su modelo, no solo probar que en tal tríada de valores, se resume la estrategia única y racional, para alcanzar el desarrollo, sino que en dichos tres factores, se encuentra sintetizado el "deber ser" del interés nacional, to que por tal razón deberá contar con el apoyo de todas las fuerzas políticas y sociales sin excepción alguna. En tal marco referencial, se viene dibujando to que se deberá de interpretar por 
neoconservador. En tal sentido, la interpretación va en el orden de mantener el sistema, el modelo de producción y las relaciones sociales derivadas, todo sustentado en el marco del capitalismo, que hace alusión al capital genérico. En otros términos el conservadorismo que profesa la nueva derecha, pretende rejuvenecer el sistema, con la finalidad de mantener las estructuras concentradas de la riqueza y del ingreso y sus expresiones derivadas de injusticia y violencia estructural.

Respecto al prefijo Neo, la intepretación que se debe efectuar, va en el sentido de hacer hincapié en las nuevas incorporaciones y/o modificaciones, que se deben efectuar al conservadorismo, con la tinalidad de presentar una nueva imagen remozada, pero que en el fondo persigue mantener la esencia de un sistema que en to político, continue sustentándose en unas prácticas políticas excluyentes, definidas en función que el proceso de toma de decisiones tanto a nivel políticosocial, como económico, seguirá respondiendo a los intereses de la clase fundamental, en nuestro caso, bajo la dirección de los intelectuales orgánicos de la nueva derecha, sin que los sectores populares organizados puedan tener mayores niveles de participación en tal proceso.

En este marco político neoconservador, el modelo que se propone ejecutar, para ejercer la hegemonia político-social, se erige a partir de los siguientes principios.

1. Democracia plebicitaria.

2. Anticomunismo pragmático.

3. Despolitización de las masas.

4. Desigualdades sociales.

Veamos a continuación, con la finalidad de ir dibujando progresivamente el modelo, qué interpretación le da a cada uno de estos principios. En este sentido, la connotación con que lee la democracia plebiscitaria, lo sustenta en los siguientes criterios:

1. La única vía que existe para alcanzar el poder político, de manera legal y legítima a la vez, se define por medio de gobiernos civiles, surgidos de procesos electorales limpios y libres, procesos que deben gozar del consenso de todas las fuerzas politico-sociales existentes en el escenario nacional, por medio de los cuales se debe disputar el poder, en igualdad de condiciones, entre todas las fuerzas políticas con existencia legal, siendo el electorado quien libremente escoja a sus gobernantes. Entendiendo este proceso como "democracia plebiscitaria".

2. Sostienen que tales procesos electorales, deben contar con la presencia de los factores que los definen, siendo éstos: partidos 
políticos, candidatos y organismos electorales que gocen de credibilidad en el electorado, siendo los últimos citados, los responsables de garantizar la existencia de un escenario político, el cual se rija por reglas, que garanticen la participación de todas las fuerzas políticas democráticas.

3. Como condición previa a las dos anteriores, sostienen que se deben construir las instituciones democráticas en las que se apoyen los procesos electorales libres, esto hace alusión directa a la existencia interna de un sistema judicial, capaz de impartir justicia independientemente de criterios políticos, económicos, sociales e ideológicos, así como también a la existencia de otras instituciones democráticas como: sindicatos, asociaciones gremiales, profesionales y humanitarios, dedicadas a vigilar por el estricto respeto de los derechos políticos, económicos y sociales de los salvadoreños. ${ }^{19}$ Otro factor que también consideran, es que un componente esencial de la democracia plesbicitaria, lo constituye la libertad de expresión y asociación, como factores por medio de los cuales se deben canalizar los cuestionamientos al sistema, en el sentido, de convertirse en los sensores del descontento social.

Otro elemento, tanto o más importante que los anteriores, en la concepción de la democracia plebicitaria, radica en que, con todos los mecanismos descritos, la nueva derecha pretende debilitar a la derecha tradicional, tiende a desplazarla de la posición y función de hegemonía que ha ejercido hasta el presente. Sin embargo, esto no debe interpretarse en el sentido, que con esta praxis la nueva derecha pretende llegar a controlar el poder político y desde esa posición ejercer la hegemonia, todo parece indicar que no es ésa la meta que persigue tal actor, sino más bien, desempenar las funciones de intelectual orgánico del actor, que tome como propias los modelos de conducción del estado formulado por ellos, en los órdenes económico, político y social y de esta manera se garantice la supervivencia y reproducción del sistema y del estado. Por último, la nueva derecha no descarta que en este actor que ejerza la hegemonía, se encuentren participando algunos de los miembros de la derecha tradicional, permeados por su ideologia y que al presente parecen estar más cerca de ellos, que de la concepción ideológica en que se enmarca la derecha tradicional. También la democracia plebiscitaria, se debe tener presente que no pone a discusión el modelo político-social y económico que propone la nueva derecha, sino al actor político que lo ha de implementar.

A este respecto el análisis que las otras fuerzas políticas efectúan, sobre este planteamiento se puede resumir en la siguiente forma: la 
derecha tradicional considera que tal esquema de democracia plebicitaria al implementarse, conducirá en el mediano plazo a un debilitamiento de la posición de hegemonia, que ha ejercido en el pasado con el consiguiente potencial peligro, de que sus intereses no continúen ocupando una situación preferencial en el ámbito estatal. Las fuerzas político-sociales, que representan los intereses de los sectores sociales de ingresos medios y bajos, que han mantenido una posición de críticas al sistema, durante estas dos últimas décadas, ven tal esquema con ciertos niveles de escepticismo; por su parte los sectores más radicalizados de tal conglomerado, han llegado a calificar esa propuesta como una nueva estrategia de dominación de la clase fundamental, que persigue el mantenimiento de las actuales estructuras. Por su parte, el actor que propone el esquema aludido, sostiene que la democracia plesbicitaria, de implementarse adecuadamente ayudará a la transformación de la estructura social de la nación, en un clima proclive a la generación de condiciones favorable al logro y mantenimiento de la paz. ${ }^{20}$ Esto no niega el reconocimiento que dicho actor hace, en el sentido de considerar, que el capitalismo y sobretodo la modalidad que ha funcionado en el pais, no es armónico y precisamente eso ha generado parte de la conflictiva situación social presente.

En niveles más específicos de cuestionamiento, a los componentes que integran y definen a la democracia plebiscitaria, organizaciones estudiantiles y gremiales, vinculadas a instituciones académicas, que históricamente han presentado un nivel de críticia constante al sistema y régimen de gobierno, sostienen que los mecanismos en que se bazará la democracia plebiscitaria, funcionarán en forma sesgada, tendiendo a favorecer a las fuerzas políticas, que representan los intereses de las diferentes fracciones de la clase fundamental.

Sectores académicos moderados, también críticos del sistema, ven en esta propuesta, algunos signos positivos que indican que pueden favorecer la creación de espacios políticos, los cuales apuntan en la dirección de un proceso de democratización; por su parte las instituciones que agrupan a los intelectuales orgánicos de la nueva derecha como FUSADES, citan en repetidas ocasiones como ejemplo de regímenes políticos disciplinados y modelo económico como el propuesto los casos de Corea del Sur, Formosa y Chile, dejando entrever su admiración por tales regímenes. A este respecto se puede efectuar diferentes y variadas inferencias políticas, considero más prudente dejar al criterio y suspicasia política del lector, llegar a sus propias conclusiones.

En relación al anticomunismo pragmático, que profesa la nueva 
derecha, éste se orienta apuntando a un anticomunismo racional, cuyo discurso y acciones responde a la realidad de la coyuntura que entrenta. Sin embargo, a pesar de que el nivel de pragmatismo, niega la validez de patrones universales de solución, en alguna medida tal anticomunismo se dirige con énfasis a desligitimar formas de organización social, que insinúen o se puedan identificar con soluciones colectivizantes, comunitaristas y socializantes, a tal tipo de alternativas inicialmente le niegan validez al estigmatizarlas como formas propias de expresiones de solución del comunismo internacional. En un segundo nivel, les contrapone sus expresiones propias, sustentadas en una visión individualista, en la que se hace énfasis que sólo la iniciativa individual y privada, se erige como una forma superior que permite adecuadas soluciones. Es decir en otros términos, a las propuestas de solución de tendencia socializante les enfrenta alternativas basadas o sustentadas en la iniciativa individual, que su creatividad se encuentra estimulada a partir de la propiedad privada. Esto, en alguna medida, explica el porqué, la nueva derecha se opone a la reforma agraria, en la modalidad de propiedad colectiva de la tierra; pero si está dispuesta a apoyar algunos niveles de redistribución de la tierra a los campesinos, pero en calidad de propietarios individuales de la misma. Debiendo esto ser visto también, al interior de un monismo ideológico; es decir, en otros términos, que sólo las propuestas de alternativas de solución emanadas de ella, son las adecuadas, mejores y únicas, que pueden conducir a la solución de la problemática que se pretende modificar.

En relación al principio de despolitización de masas, que se propone implementar, lo enmarca dentro de la estrategia global de un cierto control social, cuyo objetivo fundamental apunta a efectuar un proceso de ideologización de las masas populares, en un marco de valores ad hoc, que se deben promover a nivel de la iglesia y de las "organizaciones democráticas", constituidas para el logro de tal propósito. Por consiguiente, el proceso de despolitación, se orienta en el sentido de minimizar la infuencia y atracción que ha ejercido, en los sectores sociales de ingresos medios y bajo de la población, el marxismoleninismo y la teología de la liberación.

Respecto al primero citado, consideran que los sectores obrerossindicales, han sido penetrados con bastante facilidad por tal ideología, de manera que una estrategia orientada a neutralizar tal influencia, se debe operativizar en la constitución de asociaciones sindicales paralelas, cuya praxis se oriente en una "ideología política democrática". Referente a la forma cómo contrarrestar la aceptación de la teología de la liberación, a nivel urbano y rural, plantean concretarlo a través de las sectas cristianas protestantes fundamentalistas las que, por la forma de 
la praxis que efectúan, sustentada en una interpretación literal del discurso bíblico y creer en la validez de una concepción teocrática del poder, en el presente, sirven en forma ideal a los objetivos ideológicos políticos de la nueva derecha. En El Salvador, en estas dos últimas décadas, tales sectas cristianas protestantes fundamentalistas han proliferado, promoviendo la aceptación de valores de subordinación, pobreza, humildad y obediencia, on virtud de que son los patrones de conducta que ha practicado el cristianismo desde sus inicios, de forma tal, que las concepciones ideológicas que los rechace como normas de conducta humana, se opone al sistema mismo, del cual constituyen el centro de los valores, que generan relaciones sociales propias del mundo occidental. De esta categoría se excluye a la Iglesia Luterana Enmanuel, debido a su posición de crítica al sistema y régimen de gobierno, que ha mantenido desde inicio de la presente coyuntura conflictiva.

Referente al principio de las desigualdades sociales, este será un producto ampliado de las ya existentes, derivado de la puesta en ejecución de las medidas económicas que propone la nueva derecha, en su modelo de hegemonia a tal nivel, modelo que ha sido tratado al inicio de este capítulo. Tal hegemonía se puede decir no considera, ni siquiera a nivel marginal propuestas de redistribución de la riqueza y del ingreso; por el contrario, se enmarca mucho en la concepción de la "teoria del rebalse", según la cual en la medida que se de un mayor nivel del progreso del empresario, esta mejoría en la situación económica del sector privado, terminará por llegar a beneficiar al sector laboral; en este sentido, cifras que expresan los coeficientes técnicos de la producción del café, principal producto de la economía nacional, tanto por las divisas como por los salarios que genera, nos confirman to sehalado, respecto a la concentración del ingreso, expresándose así:

Coeficientes técnicos del sector café. ${ }^{21}$

1. Consumo intermedio total

2. Sueldos, salarios y prestaciones sociales $\quad 0.242$

3. Consumo de capital fijo

0.005

4. Impuestos indirectos netos de subsidios 0.179

5. Excedente de explotación

0.503

6. V.B.P. de cada unidad en términos monetarios

1.000

De manera que al contrastar los sueldos y salarios del sector laboral, con el excedente que se apropia el sector privado, vemos que los primeros no llegan ni al $25 \%$ del valor total; mientras que los propietarios se quedan con el $50 \%$ del mismo. 
Estas cifras nos sirven en el sentido de que expresan en alguna medida la estructura concentrada del ingreso, que históricamente ha tenido vigencia en nuestra sociedad.

Esta concentración del ingreso, beneficiando al sector privado, constituye el origen de las desigualdades económicas, que se han proyectado a lo social, político e ideológico. La nueva derecha con su modelo económico, no llega a sugerir una alteración de la estructura concentrada del ingreso, ni mucho menos de la riqueza, con la finalidad de favorecer al sector laboral, en tal sentido, se puede llegar a sostener que tal esquema, contribuirá a ampliar la brecha que separa en bo social, político e ideológico a ambos actores protagónicos de la historia salvadorefia: clase fundamental y clase subalterna.

Desigualdades que históricamente en lo político, se han manifestado por medio de un modelo de prácticas políticas excluyentes, definido por una falta de participación en el proceso de toma de decisiones políticas, de parte de los sectores sociales de ingresos bajos, de manera tal, que el poder político ha sido ejercido por los representantes de la clase fundamental, en función de los intereses de dicha clase. Estas desigualdades a nivel social dialécticamente y en forma histórica, se han manifestado en el sentido de: a mayor riqueza, opulencia y lujo de los sectores sociales de altos ingresos, los sectores sociales de bajos ingresos se sumen cada vez más en la pobreza, miseria e indigencia, como se puede constatar por las citras estadísticas que se presentan en este capitulo.

Por último, es necesario enfatizar, que el interior del esquema de pragmatismo político de la nueva derecha, es orientado en el sentido de: no reconocer aliados ni enemigos, sino sólo intereses, en este marco conceptual, no persigue el control directo del poder político, si no que apoyará en la consecución del mismo a la fuerza político-social, que tome como propios sus modelos propuestos a nivel económico, político y social.

\section{NOTAS}

1. "Poster": Carretera a Nueva San Salvador, frente a Iglesia de Guadalupe.

2. Cuñas de T.V. y Radio: Publicadas en YSKL, a partir del 2 de Oct./89 c/30 minutos y T.V. Canal 12 chora.

3. Ministerio de Salud Pública y Asistencia Social: Informe anual 1979. Departamento de Estadisticas y Epidemiologla. San Salvador, El Salvador, julio 1980, Págs. 13 a 15.

4. Ministerio de Educación: Informe anual 1980. Departamento de Estadisticas. Septiembre 1981, San Salvador, El Salvador, Pág. 17. 
5. Campaña nacional Antipalúdica: Departamento de Control de Aedes Aegipty. Informe de viviendas rociadas y población protegida. San Salvador, El Salvador, enero de 1986.

6. FUSADES: "La necesidad de un nuevo modelo económico para El Salvador". San Salvedor, El Salvador, 1985. Págs. 3 a 5.

7. "La Prensa Gráfica": San Salvador, El Salvador, julio 1989, Pág. 2.

8. "El Noticiero": T.V. Canal 6. Denuncia de directiva de ATMAG sobre 1,244 despidos de trabajadores estatales. Edición $20.00 \mathrm{~h}$. Oct. 24. San Salvador, El Salvador.

9. Francisco Lazo Marin: "Existe un pensamiento de Nueva Derecha en El Salvador". Mimoografiado. San Salvador, El Salvador, 1988, Pág. 2.

10. FUSADES: Ibidem N 6, Pág. 4.

11. FUSADES: Op. Cit., Pág. 37.

12. Juan Héclor Vidal: "La necesidad de crear la Bolsa de Valores en El Salvador". Ponencia presentada en el toro Bolsa de Valores: Su importancia y significado para El Salvador, mimeografiado. Enero 1989, Págs. 1 a 7.

13. FUSADES: Op. Cit. Págs. 37, 58 y 59.

14. FUSADES: Op. Cit. Págs. 39 y 59.

15. FUSADES: Op. Cit. Págs. 38 y 56.

16. FUSADES: "Boletín Económico y Social" N² 41, San Salvador, El Salvador. Enerofebrero, 1989. El papel del Estado, Pág. 3.

17. FUSADES: Op. Cit. № 6. Pág. 4.

18. FUSADES: Op. Cit. № 6. Pág. 58.

20.FUSADES: Op. Cit. № 6. Pág. 3 a 5.

21. Francisco lbisate: "A los cien dias de gobiemo, ¿Hacia dónde vamos? ECA N 490 91. Agosto-septiembre, 1989. San Salvador, El Salvador, Pág. 657. 